Cuad. invest. hist., Brocar n. 15 (1989) Págs. 119-136

\title{
LOS MALOS TRATOS A LAS MUJERES EN CASTILLA EN EL SIGLO XVII
}

\author{
Pedro Luis Lorenzo Cadarso
}

\begin{abstract}
RESUMEN
Este articulo, basado principalmente en documentación judicial, analiza, desde una perspectiva eminentemente empírica, el drama social de la violencia antifemenina en la Castilla del siglo XVII, prestando atención especial a sus facetas más duras: la violencia de tipo sexual y las llamadas «venganzas de honor». Se intenta relacionar el problema con la actitud que ante él tomaban las autoridades judiciales y los moralistas cristianos. Por último, se estudia el papel que la situación de inferioridad, jurídica y moral, de la mujer jugaba en el sostenimiento del orden social.

This article, based principaly in judicial documentation, analyses, from a perspective eminently empiric, the social drama of antifemenine violence in Castilla kingdom in XVII century, with special attention at their heaviest expresions: the sexual violence and the «honour vengances». It is connected the problem with the attitudes of the judicial authorities and the christians writers. At last, it is studied the function that the inferiority of the women had in the preservation of the social order.
\end{abstract}

\section{ASPECTOS SOCIOLOGICOS Y CULTURALES DEL PROBLEMA}

En el trato dado a las mujeres, el siglo XVII se caracteriza, al menos desde el punto de vista de la cultura escrita, por un recrudecimiento de la literatura misógina más extremada'. Sin embargo, aunque resulte paradójico, los pensadores renacentistas ya habían iniciado el camino que llevaría a la dignificación de la condición femenina y el proceso no parece que se detuviera, más bien todo lo contrario ${ }^{2}$.

1. vid., Mariló Vigil, La vida de las mujeres en los siglos XVI y XVII, Madrid, 1986

2. Para una visión global europea, vid., Romeo de Maio, Mujer y Renacimiento, Madrid, 1988; para el caso inglés, dentro del mundo protestante, vid., Ch. Hill, El mundo trastornado, Madrid, 1983, pp. 297-301. 
Desde un punto de vista historiográfico, parecen coexistir dos tesis contrapuestas. La primera de ellas vendría a decir que la situación de las mujeres en los siglos XVI y XVII fue empeorando con el paso del tiempo o que, cuando menos, siempre fue peor que la existente en la Edad Media ${ }^{3}$. La segunda opina justamente lo contrario, que de la mano del humanismo renacentista y de la propia evolución socioeconómica general, las mujeres alcanzaron cotas de libertad desconocidas hasta entonces, del mismo modo que sus derechos cívicos fueron cada vez más protegidos por la legislación ${ }^{4}$.

Parece poco probable que la situación femenina pudiese empeorar notoriamente. En primer lugar, porque la posición de partida era ya patética: la mujer era, al menos desde la época visigoda -según se trasluce de su legislación-, poco más que un objeto, dependiente de padres, tutores o esposos, con escasa capacidad para hacer valer sus derechos o imponer sus criterios ${ }^{5}$. Después, los derechos que le reconocieron los fueros medievales eran, ante todo, económicos, tendentes a proteger su dote y su herencia, principalmente. En segundo lugar, no cabe duda de que la legislación, aunque fuese tímidamente, fue coartando cada vez más el poder absoluto que padres, tutores y, sobre todo, esposos, habían tenido tradicionalmente sobre la mujer. En el siglo XVII ya no estaba garantizada de antemano la impunidad y era muy arriesgado para un esposo que se creyese traicionado o simplemente ofendido el tomarse la justicia por su mano: se arriesgaba a ser procesado casi con absoluta seguridad ${ }^{6}$.

A esta situación se llegó, desde mi punto de vista, por dos motivos. En primer lugar, por la labor de un nutrido grupo de moralistas que, aun viendo con buenos ojos la situación de inferioridad jurídica y moral de la mujer, criticaban los abusos indiscriminados a los que podía dar lugar el poder absoluto de padres y esposos: les parecían intolerables las palizas y las venganzas de honor sangrientas, considerándolas contrarias a la ética cristiana ${ }^{7}$, y los más radicales -como, por ejemplo, Boccaccio- se oponían con dureza, incluso, a la costumbre de meter monjas a las doncellas por intereses patrimoniales $^{8}$. En segundo lugar, con el desarrollo del Estado Absoluto en Castilla, éste, en coherencia con sus principios políticos y jurídicos, tendió a intervenir cada vez con mayor decisión en todas las disputas privadas. Esto, aunque no sea fácil de demostrar, tuvo que suponer una mejora para las mujeres, que muy a menudo encontraban en los tribunales protección ante las arbitrariedades o intenciones criminales de padres y esposos $^{9}$. Ciertamente, acudir a los tribunales sólo estaba al alcance de las mujeres con un cierto nivel económico y aun en estos casos la solución que se le daba, ante un intento de asesinato por parte de su esposo, por ejemplo, era dudosamente favorable a la mujer:

3. El ejemplo más claro de esta tesis es J. Gentil da Silva, «La mujer en España en la época mercantil: de la igualdad al aislamiento», en La mujer en la Historia de España, Madrid, 1978, pp. 11-33

4. Para el caso español vid., Mariló Vigil, ob. cit., pp. 24-38

5. vid., VV.AA., La condición de la mujer en la Edad Media, Actas del Coloquio hispanofrancés, Casa de Velázquez, Madrid, 1986; especialmente los artículos: R. Pastor, «Por una historia social de la mujer hispano-medieval. Problemática y puntos de vista», pp. 187-214, y R. Rodríguez Gil, «Las posibilidades de actuación jurídico-privadas de la mujer soltera medieval», pp. 107-120

6. vid., por ejemplo, J. Deleito y Piñuela, La mala vida en la España de Felipe IV, Madrid, 1987, pp. 79-83.

7. vid., Mariló Vigil, ob. cit., pp. 102-105 y 148-156.

8. cfr., Boccaccio, De mulieribus, cit., en Romeo de Maio, ob. cit., pp. 227-256.

9. En las memorias de la Monja Alférez se narra un caso de este tipo, $c f r$., Catalina de Erauso, Memorias de la Monja Alférez, Madrid, 1974, pp. 71-75. 
ingresarla en un convento. Pero, aunque algunos piensen lo contrario, parece probable que el derecho del Estado Absoluto, inspirado en el romano, fue un avance ${ }^{10}$.

Todavía podríamos citar una tercera tesis, ésta mucho menos sólida que las dos anteriores. Según ella, Castilla habría sido un territorio donde las mujeres eran respetadas al máximo, tanto en la vida privada como en sus derechos patrimoniales ${ }^{11}$.

Un hecho que no debe perderse de vista y que queda patente nada más consultar unos pocos documentos sobre la vida real de las mujeres en el siglo XVII, es la existencia, por así decirlo, de una «doble moral». Por un lado, la mayor parte de los moralistas cristianos y la propia legislación, condenaban los malos tratos a las mujeres y cualquier otro tipo de abuso ${ }^{12}$. Sin embargo, en la práctica, la ética dignificadora de la mujer tuvo una dificultosa introducción en los hábitos de comportamiento e incluso la mayoría de los jueces preferían inhibirse ante temas tan espinosos como eran las disputas hombremujer. La propia legislación era muy a menudo contradictoria. Por ejemplo, la Nueva Recopilación de las Leyes de España, en 1567, seguía aceptando las venganzas de honor sangrientas, aunque fuese exigiendo la participación de los tribunales.

De hecho, la dignificación de la mujer entraba en franca contadicción con buena parte de los principios básicos sobre los que se asentaban en el orden y la jerarquía social en el siglo XVII. La nobleza, tanto los nobles titulados como los hidalgos que formaban las élites urbanas, respondieron a la aparición de nuevos grupos sociales en ascenso (burgueses enriquecidos) con el reforzamiento de los criterios que les distinguían de ellos: principalmente el linaje -la condición social heredada- y el prestigio social que traía consigo el ejercicio del poder y una vida de rentista. La mujer ocupaba, por razones obvias, un papel clave en la transmisión a los descendientes de un determinado status social y, por supuesto, en la honorabilidad de su familia y esposo. De este modo, «honor», entendido como el reconocimiento social de pertenencia al grupo social privilegiado, al cual se accedía por la vía del parentesco, y «nobleza», pasaron a ser dos cuestiones inseparables ${ }^{13}$.

Ejercer un riguroso control sobre la vida cotidiana de la mujer pasó a ser así una necesidad irrenunciable: se aislaba en sus domicilios a las doncellas para evitar que hubiese alguna duda sobre su honestidad (y virginidad) en el momento de entregarla a su esposo $^{14}$, se hacía lo mismo con las casadas para tener la certeza de la legitimidad de los hijos $^{15}$, se ingresaba en conventos a las hijas para contar con más dinero con el que dotar a sus hermanas, etc.. Si la mujer ponía en peligro con su comportamiento los objetivos de sus padres o esposos, no sólo hipotecaba su propio futuro, sino que cuestionaba la honorabilidad de quien tenía la obligación de custodiarla. Entonces, el marido, el padre, el hermano o quien tuviera esa misión, debía demostrar públicamente que el hecho no se

10. Romeo de Maio, ob. cit., p. 94, piensa que el derecho romano empeoró la situación de la mujer, siendo ésta mejor en las zonas con pervivencia del derecho consuetudinar consuetudinario, como Inglaterra o Cataluña.

11. Esta tesis la sostiene A., Domínguez Ortiz, El Antiguo Régimen: Los Reyes Católicos y los Austrias, Madrid, 1981, pp. 194-195.

12. vid., Mariló Vigil, ob. cit., pp. 102-105. Cervantes defendió también estas ideas, $c f r$., El celoso extremeño y El curioso impertinente.

13. vid., Gómez Centurión, C., «La familia, la mujer y el niño», en Alcalá-Zamora, J.N., La vida cotidiana en la España de Velázquez, Madrid, 1989, pp. 169-194; Redondo, A. (ed.), Amours légitimes, amours illégitimes en Espagne (XVI-XVII siècles), Paris, 1989; López Cordón Cortezo, M. ${ }^{a}$ V., «La situación de la mujer a finales del Antiguo Régimen», en VV.AA., Mujer y sociedad en España (1700-1975), Madrid, 1982, pp. 47-107; Flandrin, J.L., La moral sexual en Occidente, Barcelona, 1984.

14. vid., R. Pastor, art. cit., p. 198

15. vid., Mariló Vigil, ob. cit., p. 143 
había producido con su consentimiento: surgía entonces el recurso de la violencia, la sangre como mecanismo para lavar la honra ${ }^{16}$.

Como cuestión social que era, no todos los sectores de la sociedad respondían de igual manera ante este problema. Por un lado, las mujeres de la alta nobleza estaban, en cierto modo, por encima de él y no precisaban de la reputación social para mantener su status. El pueblo llano, éste por necesidad económica, no podía permitirse el lujo de enclaustrar a sus mujeres, de modo que éstas gozaban de gran libertad de movimientos. El aislamiento en el domicilio familiar, los matrimonios de conveniencia, las hijas ingresadas como monjas siendo aún niñas ${ }^{17}$, etc., eran prácticas especialmente habituales entre lo que algunos autores definen como «clases medias urbanas» ${ }^{18}$ que, en un sentido estricto, son las élites urbanas, compuestas por la baja nobleza -hidalgos ricos y algún señor de vasallos de bajo nivel-y por vecinos ricos del estamento general -mercaderes, algunas profesiones liberales, campesinos ricos, etc.-. Para este grupo social, llevar a cabo una estricta estrategia matrimonial constituía uno de los pilares básicos sobre los que se sustentaba su condición de élite en el marco local. Los linajes hidalgos utilizaban a sus hijas para reforzar los lazos endogámicos y de clientela con los que se relacionaban entre sí y con las ramas familiares ubicadas en otras localidades o en la propia Corte ${ }^{19}$. Los pecheros ricos, deseosos de ingresar en el estamento nobiliario, se valían de sus hijas -mucho más que de sus hijos varones- para emparentar con los nobles por la vía del matrimonio, asegurando así la condición nobiliaria a sus nietos y aumentando el status de toda la familia.

La virginidad y la buena fama de las doncellas eran pues valores económicos y sociales y la mujer se hacía portadora de la honorabilidad de todo su linaje familiar. La importancia dada a este asunto era tal, que cualquier hombre digno debía estar dispuesto a utilizar la violencia para defender el honor de los suyos. El teatro nos ofrece una buena prueba de hasta qué punto esto era así, haciendo del tema de la honra, entendida casi siempre en sus aspectos sexuales, uno de sus ejes centrales ${ }^{20}$. El nivel social de un hombre, e incluso sus cualidades morales, venían determinados, entre otros factores, por el comportamiento sexual de su madre; recordemos a este respecto que la práctica totalidad de los pícaros de la literatura (Guzmán de Alfarache, Lazarillo, el Buscón Pablos) comenzaban su vida marginal desde la propia cuna, al ser sus madres adúlteras y sus padres cornudos consentidos.

No es fácil saber hasta qué punto estos principios de comportamiento eran seguidos por la generalidad de los hombres y todavía lo es menos el saber si las mujeres los aceptaban de buen grado.

Las relaciones extramatrimoniales parece que eran frecuentes y aún lo eran más los flirteos con pretendientes. El aislamiento en el recinto doméstico nunca era total, las

16. vid., Maravall, J.A., ob. cit., pp. 65-79 y 134-145; Bartolomé Bennassar, Los españoles. Actitudes y mentalidades, Barcelona, 1978, p. 206.

17. Catalina de Erauso, en la obra citada, cuenta que fue ingresada en el convento a los cuatro años de edad.

18. Por ejemplo, Mariló Vigil, ob. cit., pp. 18-38.

19. vid., Bartolomé Yun Casalilla, Sobre la transición al capitalismo en Castilla, Salamanca, 1987, pp. 224-225.

20. vid., Delpech, F., «La leyenda de la Serrana de la Vera», en La mujer en el teatro y la literatura del siglo XVII, Tolouse, 1978, p. 35; y Maravall, J.A., Teatro y literatura en la sociedad barroca, Madrid, 1972. 
mujeres, incluso las más enclaustradas, salían a la calle para ir a misa, al mercado los días de feria, para ir de visita a casa de sus familiares, etc. En esos momentos resultaba inevitable el contacto con los hombres y de ahí, en una proporción que desconocemos, se llegaba a las relaciones sexuales. Según algunos autores, el «amor cortés» era intimamente deseado por todas la mujeres, convirtiéndose así en un mecanismo de rebeldía «para tratar de liberarse de la tutela asfixiante de moralistas, padres y maridos, para dejarse adorar por suspirantes caballeros» ${ }^{21}$. El amor en general, en la medida en que no estaba sujeto a estrategias familiares, tenía siempre cierta carga de rebeldía, y el matrimonio por amor «aparecia ante ellas como una liberación, un ingreso en la edad adulta y una forma de emancipación de la autoridad paterna $\rangle^{22}$. Para otros autores, no tan optimistas, los escarceos ilegítimos eran el resultado de la propia situación de postración de la mujer:

«La mujer, cuyo entorno vital es estrecho, es fácil objeto de engaño. Está desinformada, ignora el juego de las intenciones masculinas, que la acercan a una sexualidad, quizá no buscada, frecuentemente admitida.» ${ }^{23}$

La situación de inferioridad de las mujeres era algo consustancial al orden social vigente. El aislamiento era una medida preventiva frente a escarceos amorosos que afectaran a su reputación y a la estrategia matrimonial de la familia y asimismo una garantía de que su prometido no encontraría excusa alguna para romper el compromiso de matrimonio ${ }^{24}$. Los malos tratos, aunque criticados por los moralistas cristianos, eran muy a menudo considerados por estos mismos como un mal menor, al pensarse que con ellos el marido o el padre aseguraría la obediencia de la mujer ${ }^{25}$, dificultando así la infidelidad o las desavenencias conyugales. Ejercer un riguroso control sobre las mujeres, en el que el aislamiento y la mano dura suplantaban al diálogo, se justificaba doctrinalmente aludiendo a las características de la psicología femenina, que la situaban en inferioridad moral frente al hombre. Incluso fray Martín de Córdoba, en una obra nada sospechosa de misoginia por tratarse de un alegato a favor de los intereses dinásticos de Isabel la Católica, se hace eco de esos tópicos diciendo que las mujeres son ${ }^{26}$ :

- Intemperadas: «son más carne que espiritu», con lo que se entregan con mayor facilidad a los apetitos carnales.

- Extremosas: Van de un extremo a otro, según la personalidad de cada una, sin mantener nunca posturas prudentes o equilibradas.

- Parleras y porfiosas: "Ser parleras les viene de flaqueza, ca veyéndose flacas para poner el negocio a las manos, pónenlo a palabras; que lo que no puede la espada, que lo haga la lengua».

- Móviles e inconstantes: "lo cual les viene de la flebe complexión del cuerpo», haciéndoseles difícil ajustar su comportamiento a los principios éticos.

21. Mariló Vigil, ob. cit., pp. 61-78

22. ibid., pp. 79-91

23. R. Pastor, art. cit., p. 214

24. ibid., p. 198; y Atienza, Ignacio, «Aunque fuera con una negra si Su Majestad así lo desea», en Gestae. Familia y Sociedad, Murcia, 1989, no 1, pp. 31-52

25. vid., Mariló Vigil, ob. cit., pp. 102-105, y R. de Maio, ob. cit., p. 107

26. cfr., Fray Martín de Córdoba, Tratado que se intitula Jardín de las nobles doncellas, Biblioteca de Autores Epañoles. Prosistas castellanos del siglo XV, Madrid, V. II, t. 171, pp. 71 y ss. 


\section{P.L. LORENZO CADARSO}

La misoginia, como ya hemos dicho antes, se recrudeció en el siglo XVII, quizás porque las mujeres, en su vida cotidiana, no ajustaban su comportamiento a las propuestas de los moralistas ${ }^{27}$. De todos modos, la misoginia formó parte de un recrudecimiento de las críticas a la vida disipada, general en toda Europa ${ }^{28}$, al desenfreno sexual, que para muchos moralistas amenazaban con destruir al Estado. En Castilla, este estado de opinión alcanzó su pleno desarrollo durante el reinado de Felipe IV $^{29}$, formando parte del debate sobre la decadencia del reino, y la primera respuesta que se dio desde el poder fue la represión ${ }^{30}$ : leyes contra el celibato (1623), contra la prostitución (1639), contra la simonía, contra el adulterio, contra las aberraciones sexuales (ya desde 1598), contra los hijos ilegítimos e incluso contra el propio teatro $(1646)^{31}$. La mujer, considerada desde la Alta Edad Media como un ser moralmente peligroso, incitador al pecado y a la degeneración de las costumbres ${ }^{32}$, fue colocada en el centro de la atención de los moralistas más furibundos.

\section{LOS ABUSOS SEXUALES}

Es imposible analizar adecuadamente el problema de los abusos sexuales de que eran objeto las mujeres del siglo XVII sin tener en cuenta algunos factores:

a) La impunidad con que en la práctica podian actuar los agresores. Había, en primer lugar, una serie de estatutos y privilegios jurídicos de los que podían valerse los agresores para escapar a la justicia: retraerse en una iglesia o convento ${ }^{33}$ y evitar así la cárcel; alegar gozar del fuero militar, eclesiástico o de la Inquisición, obligando al juez instructor del sumario a inhibirse en el conocimiento del caso; simplemente fugarse del lugar de los hechos, entorpeciendo así el procedimiento amparándose en que las autoridades judiciales de primera instancia sólo tenían jurisdicción en el marco local, y, si se huía a uno de los reinos vecinos (Aragón, Navarra, etc.), era casi imposible extraditar al fugado.

En segundo lugar, con mucha mayor asiduidad, el agresor era protegido por sus parientes y amigos, entre quienes, muy a menudo, se encontraban las autoridades judiciales locales. Demostrar un abuso sexual no es técnicamente fácil, normalmente no hay más testigos que la víctima y el agresor $y$, si no se realizaba un reconocimiento médico en las primeras horas -habitualmente lo llevaban a cabo las matronas-, no era posible probar judicialmente las lesiones producidas en el forcejeo ni que la penetración se hubiese consumado. Si los jueces de primera instancia no actuaban con la máxima diligencia en los primeros momentos, la víctima se veía en la más absoluta indefensión.

27. Esta es la opinión de Mariló Vigil, en ob. cit.

28. vid., H.R., Trevor Roper, Religión, Reforma y cambio social, Madrid, 1985, pp. 59-63

29. vid., Deleito y Piñuela, ob. cit., pp. 21-74; y J.H. Elliot, «Introspección colectiva y decadencia en España a principios del siglo XVII», en Poder y sociedad en la España de los Austrias, Barcelona, 1982. 205-223

30. vid., Rodríguez Gil, R., art. cit., pp. 107-120

31. cfr., Maravall, J.A., Teatro y literatura en la sociedad barroca, Madrid, 1972, p. 35.

32. vid., Romeo de Maio, ob. cit., pp. 41-67; y Vito Fumagalli, Cuando el cielo se oscurece. La vida en la Edad Media, Madrid, 1988, pp. 67-74

33. vid., Deleito y Piñuela, ob. cit., pp. 100-102 
b) Las dificultades que el aislamiento en sus domicilios de las mujeres y los matrimonios de conveniencia ponian a las relaciones hombre-mujer, sobre todo entre las mujeres pertenecientes a las élites locales, quienes con mayor rigor padecían estas prácticas. El amor, entre este tipo de mujeres, se convertía necesariamente en un asunto extramatrimonial $^{34}$ y que rompia las estrategias matrimoniales de sus familias. El resultado era que muchas de las relaciones sexuales ilegítimas que se denunciaban habían sido consentidas por las supuestas víctimas, y eran sus familiares y esposos quienes efectuaban la denuncia, con el objeto de proteger los intereses de su linaje, no los de la mujer. En otras ocasiones, cuando se trataba de abusos sexuales en un sentido estricto, también se anteponían los intereses del linaje a los de la víctima, y la familia se avenía a cobrar una indemnización, mientras que la mujer era encerrada en un convento ${ }^{35}$.

c) Los serios problemas que se le planteaban a una mujer de cara a su futuro matrimonio si denunciaba los intentos de abusos sexuales o su consumación. Recurrir a los tribunales significaba dar publicidad al asunto y las sentencias de éstos en ningún modo la rehabilitaban socialmente, limitándose a compensar a su familia o a su marido por lo sucedido, y eso cuando no era ingresada en un convento ${ }^{36}$. Para evitar esta situación, era muy habitual que las mujeres ocultaran los hechos y trataran de convencer a su agresor de que se casara con ellas o de echar tierra sobre el asunto.

Veamos a continuación algunos ejemplos de lo dicho hasta ahora:

A comienzos del verano de 1657, en Huete (Cuenca), don Cristóbal Fernández de Soto, hidalgo, viudo de treinta años, comenzó a hacer «maquinaciones y diligencias»" con el objeto de acostarse con María Sánchez, hija del boticario Juan Sánchez de Mena, alcalde de la Sta. Hermandad por el estamento de los hombres buenos. La muchacha vivía en un aislamiento riguroso, de modo que don Cristóbal se valió de dos de sus criadas para enviarle «regalos de cosas de comer» y «cartas en que le enviaba a decir que le queria hablar». Por fin, el siete de agosto de 1657 consiguió hablar directamente con María Sánchez, ella misma lo contó así:

«...el sobredicho la habló a esta declarante, por las junturas de las tablas de la puerta de la botica de su padre, una noche como a las doce horas de ella. Y en el discurso de lo que entrambos hablaron, dijo esta declarante al dcho. don Cristóbal Fernández que qué intentaba, que mirase que era doncella, a lo cual respondió el sobredicho que no se habia de casar con ella, y sin embargo la respuesta, confirieron entrambos la forma para que el dcho. entrase en casa del padre desta declarante...»

Probablemente estemos ante una historia de amor, pero a la que hombre y mujer acudían con distintos propósitos. La muchacha, entre engaños y promesas, se vio arrastrada hacia donde no deseaba:

34. vid., R. de Maio, ob. cit., p. 106, y I. Atienza, art. cit., p. 35

35. Recordemos, aunque no encaje por completo, el caso narrado por Calderón en El alcalde de Zalamea, en el que con la víctima, de no casarse con ella su agresor, sólo se barajaban dos posibilidades: asesinarla o recluirla en un convento.

36. Así ocurría en El tejedor de Segovia de Alarcón

37. Este caso se vio ante el Consejo de Castilla en 1658, a raíz de un memorial de amparo enviado por la familia de la víctima. Archivo Histórico Nacional (A.H.N.), Consejos, leg. 25. 632 
«... y el dcho. don Cristóbal Fdez. la persuadió a esta declarante con ruegos y promesas de ayudarla, para ponerla en estado a que tuviese asceso y acto carnal; con lo cual esta declarante vino en la voluntad del dcho. don Cristóbal, el cual la hubo y gozó y acabó de romper y quitar su virginidad...»

En realidad, ella sabía de antemano que un hidalgo perteneciente a uno de los principales linajes de la ciudad, hijo de un regidor perpetuo y sobrino del teniente del corregidor, no se casaría nunca con la hija de un boticario, de modo que aceptó el papel de amante una vez que perdió la virginidad. Además tenía ya 28 años y era, en cierto modo, casi una solterona con pocas posibilidades de encontrar marido.

Durante casi cinco meses, don Cristóbal visitó asiduamente la alcoba de su amante, saltando por su ventana desde el corral de la casa. El ocho de enero de 1658 el padre los sorprendió, los encerró por fuera con llave y avisó al corregidor. Los poderosos parientes de don Cristóbal movieron sus influencias y el corregidor primero y el Consejo de Castilla después decretaron que don Cristóbal sufriera como único castigo un arresto domiciliario, dictando igual sanción contra María Sánchez. Las acusaciones de cohecho que reiteradamente hizo el padre no sirvieron para nada.

Como puede verse, desde el punto de vista de la doncella no hubo violación, pero eso era lo menos importante, sino que lo que realmente contaba era el ultraje cometido contra su familia. De modo que don Cristóbal fue procesado por estupro (violación de una doncella) y si no terminó en la cárcel fue por las influencias de su familia y por lo dificultoso que resultaba probar jurídicamente que él había sido el estuprador una vez que habían transcurrido cinco meses desde su consumación. La muchacha no sólo no fue tenida en cuenta, sino que se la procesó como cómplice por haberlo consentido gustosamente.

La indefensión en la que solían quedar las mujeres violadas conducía, en muchos casos, a que éstas intentaran solucionar su problema al margen de los tribunales y de sus familiares, aferrándose a la esperanza de que su violador se casara con ellas y quedasen así encubiertos los hechos. Sólo cuando esa esperanza se mostraba vana osaban denunciar lo ocurrido. Un ejemplo de esto lo encontramos en esa misma ciudad, en Huete, a comienzos de $1628^{38}$. La víctima fue doña Petronila Torralta, de 19 años, hidalga y analfabeta. Era huérfana y vivía con su tía viuda, la cual la mantenía, como era norma, en el más absoluto aislamiento. Don Juan de Orduña, joven hidalgo, comenzó a pretenderla en octubre de 1627 , pero todos sus planes fracasaban y ni tan siquiera logró hablar con ella.

Cuando su tía falleció se trasladó a casa de otra de sus tías, doña Petronila de Parada, entonces don Juan, aprovechando a una criada de don Martín Manuel, tío asimismo de Petronila Torralta, consiguió por primera vez hablar con ella personalmente:

«...y alli, con ocasión que quería darle el pésame de su tía, la invió a llamar con Maria, criada del dcho. Martín Manuel, que bajase al portal, no entendiendo dcha. moza cosa ninguna desta declarante, por no parecer descortés, bajó y estuvo con el dcho. don Juan hablando. Y habiéndole dado el pésame, le dijo que bien sabia el tiempo que la andaba solicitando y que nunca habia tenido la dicha de poderla hablar y que deseaba

38. Este caso fue tramitado por un juez de comisión enviado a Huete por el Consejo de Castilla. A.H.N., Consejos, leg. 27.701 


\section{LOS MALOS TRATOS A LAS MUJERES EN CASTILLA EN EL SIGLO XVII}

mucho de servirla; y como esta declarante estaba llorando por la dcha. su tía, le dijo también que la quería limpiar las lágrimas, y al punto que esta declarante le oyó decir la dchas. palabras, le dejó con la palabra y se entró...»

La joven no se atrevió a contar nada a su familia. Don Juan de Orduña, ayudado por la misma criada, se introdujo en casa de la tía de la joven y cuando ésta regresó a casa:

«...la tiró de la ropa y, reconociéndole esta declarante, se fue a subir por la escalera huyendo y le dijo que no la persiguiese y que si queria entrar en su casa habia de ser primero dándola cédula de casarse con ella, y el dcho. don Juan la respondió que sí lo haría y que no le diese tanta priesa. Y con estas razones, por fuerza y contra la voluntad desta declarante, se fue subiendo las escaleras el dcho. don Juan, alagándola y prometiéndola que haría todo lo que quisiese, hasta que estuvo en la cocina de la casa, y siempre la tenía asida a esta declarante y aunque procuró desasirse del susodicho no pudo, porque la echó en unas almohadas que estaban en la cocina. Y visto por esta declarante la resolución del dcho. don Juan, quiso dar voces, el cual la tapó la boca, con lo cual tuvo liso el susodicho de aprovecharse desta declarante carnalmente, estrupándola y llevándola su virginidad, por fuerza e contra su voluntad $e$ haciéndola mucho daño; con lo cual se fue el dcho. don Juan, diciendo a esta declarante que volvería y la traería la cédula; y esta declarante se quedó llorando de la fuerza y vio lo que el dcho. don Juan la habia hecho...»

Ante la joven se abrían dos posibilidades: denunciar los hechos $\mathrm{y}$, lógicamente, darles publicidad o confiar en que don Juan cumpliera su palabra y le trajera la cédula ${ }^{39}$. Optó por la segunda y no encontró otra manera de hacer que don Juan cumpliera su promesa que franquearle repetidas veces la puerta de su dormitorio:

«...y todas las dchas. noches le pedia esta declarante la hiciese la dcha. cédula de casarse, dándole papel y tinta para ello, y él la decía que (ya) la haria por allá fuera (...) y porque esta declarante le decia la habia engañado en no haberla dado la cédula que la prometió, él la decia «pues si no basta darte palabra de casarme contigo». Y visto lo susodicho y que el dcho. don Juan no trataba sino de traerla en palabras, se determinó de dar cuenta a sus tíos...»

En este caso que hemos narrado, la joven no mantuvo la esperanza más que unas semanas, pero en otras ocasiones el engaño duraba años. En Nájera (La Rioja), por ejemplo, en 1689 fue denunciado por María de Lisarre un caso similar ${ }^{40}$ :

«...habrá diez y seis años, poco menos, que teniéndo mi parte catorce de edad, don Antonio del Castillo, vecino de la dcha. ciudad, habiendo encontrado a mi parte una tarde en el campo en uno de los barrios de dcha. ciudad, pasando mi parte por junto a un huerto del dcho. don Antonio, con muchas persuasiones e instancias, solicitó a mi parte para que condescendiese con él en torpes libiandades. Y habiéndose resistido mi parte diciendo era doncella honesta y recogida y que no podia faltar a la honesta reputación con que siempre habia procedido, a lo que el dcho. don Antonio replicó diciendo se casaria con ella. Y repitiéndole esta palabra y debajo de ella, persuadida

39. La cédula de matrimonio era un documento notarial por el que se comprometía un matrimonio y su incumplimiento obligaba a quien se retractara a indemnizar a la otra parte y, de no hacerlo, constituía un delito penal.

40. A.N.H., Consejos, leg. 26.331 


\section{P.L. LORENZO CADARSO}

de sus instancias y aún con violencia, logró lo que solicitaba, quedando mi parte sin la integridad que tenia. $Y$ viéndose en este estado, continuaron en amistad ilicita hasta el viernes de Ramos del año pasado, en que salió mi parte de su casa, habiendo tenido en este tiempo de el dcho. don Antonio siete hijos a luz y dos malos partos, habiéndole dicho en todo este tiempo el dcho. don Antonio se casaría con ella, teniéndola engañada y padeciendo graves molestias en su persona y hacienda, trayéndola fugitiva $y$ ausentándola de diferentes justicias que la buscaban para apartar la ocasión de dcha. amistad...»

Don Antonio había mantenido a la joven engañada basándose en aplazar una y otra vez el matrimonio: primero le dijo que se casarían cuando él terminara la carrera de derecho, luego que cuando tuviese dinero y ella sólo asumió el engaño cuando don Antonio decidió hacerse cura y se trasladó a Cárdenas (La Rioja) para hacerse cargo de la parroquia.

No siempre era la promesa de matrimonio lo que hacia que las violadas no denunciaran lo sucedido, a veces era el simple temor de sufrir represalias, que dada la actitud de los tribunales ante estos asuntos era un posibilidad muy real. Esta fue la causa de los sucesos de Villalva de Huete (Cuenca) de 16324!

«...estando mi hermana el viernes pasado, que se contaron diez y ocho deste presente mes de junio, escardando un trigo que tengo en el término desta villa (...) sola en dcha. heredad, siendo doncella virgen y honesta y de muy buena fama, opinión y reputación de la gente principal desta villa, el dcho. día, a medio día poco más o menos, yendo Alonso Chico a su trigo, viéndola sola y en el campo, acometió con ella y la derribó en el trigo y peleó con ella y violentamente y por fuerza la estrupó, corrompió y hubo su virginidad y forzola, sin embargo de que ella se resistió y defendió y le daba puñadas al dcho. Alonso Chico en las narices y le hizo sangre en ellas (...) y después de estrupada y desflorada y forzada, la amenazó para que callase y no dijese nada, y para moverla a ello y a que no se querellase ante Vuestra Majestad, ni diese cuenta de la dcha. fuerza ni se viniese a entender semejante caso ni delito, le dijo que si lo decia la pondrian presa, $y$ dándole crédito como muchacha lo calló por entonces...»

El asunto sólo salió a la luz porque unas semanas después la joven cayó enferma a causa de las lesiones que sufrió durante la violación. En realidad, los temores de la muchacha no estaban en absoluto infundados, como se quejaba su hermano tres meses después:

«...habiéndose querellado Juan del Peral, su hermano, ante el alcalde y estando el susodicho Aionso preso, habia sido por forma y como si no lo estuviera, y desde el primer dia habia andado libremente por la villa, a vista del hermano y parientes de la dcha. Mariana del Peral, dando ocasión a que sucediera una desgracia, porque respecto de ser el susodicho Alonso Chico hijo de Gregorio Chico, regidor perpetuo de la dcha. villa, y pariente muy cercano del alguacil mayor, que tenía voz y voto en el Ayuntamiento, $y$ de otras personas que tenian mucha mano con la justicia, se estaba con grande escándalo de los vecinos libre, entre quienes era notorio el delito tan grave que se habia hecho...» 
Cuando Juan del Peral informó de lo sucedido al Consejo de Castilla, su familia fue presionada por los personajes más poderosos de la ciudad, por el Ayuntamiento y por el alcalde ordinario. Cuando llegó el juez de comisión enviado por el Consejo a la villa, no pudo hacer sino recoger en su sentencia el acuerdo privado al que habían llegado las partes. Al principio, el hermano de la víctima solicitaba que se aplicase la ley con todo su rigor y exigía además una cuantiosa indemnización:

«... le condene en dos mil ducados, para que con ellos pueda la dcha. mi hermana remediarse y pasar su vida y hallar con ellos marido, igual que lo hallara sin ellos a no estar desflorada...»

En el acuerdo privado, el hermano aceptó una indemnización que servía para poco más que para cubrir los gastos judiciales que habían tenido y una sanción contra el violador de seis años de destierro de la villa:

«...por servir a Dios Nuestro Señor y, principalmente, por haber intervenido en ello pe personas principales y ser más útil y conveniente para la dcha. menor no tener pleitos...»

\section{LAS VENGANZAS DE HONOR}

La reputación y la buena fama eran valores de suma importancia en Castilla durante el siglo XVII. En ellos confluían, por un lado, la opinión que los demás tenían de uno y, por el otro, la pertenencia a un linaje, la sangre heredada: se trata del famoso concepto del honor. La mujer tenía un papel importantísimo que cumplir en este asunto; tanto es así que la idea más extendia era que debía de entregarse por completo a salvaguardar el prestigio de su linaje:

\section{"Que la mujer corresponde} a su sangre y no a su ser ${ }^{42}$

Para ello, los modelos de conducta le exigían regirse por una serie de principios: la modestia, la obediencia, el recato y la castidad ${ }^{43}$. Sin embargo, no siempre las mujeres podían o querían adaptarse a ellos. Cuando así sucedía, lo de menos era que estuviesen perjudicando su prestigio personal, sino que lo realmente importante es que cuestionaban el de sus familias, sus esposos o, incluso, el de sus amantes. La respuesta por parte del hombre ultrajado era, muy frecuentemente, utilizar la violencia.

\section{A) Los amantes despechados}

En un plano teórico, tanto moralistas como juristas parece que estaban de acuerdo en que la falta de castidad o cualquier otro delito contra su honorabilidad en las mujeres solteras sin familia era sólo un pecado moral, mientras que si la tenía pasaba a ser una

41. A.H.N., Consejos, leg. 25.533

42. Lope de Vega, El duque de Viseo, cit. en Maravall, Teatro..., ob. cit., p. 98

43. vid., Mariló Vigil, ob. cit., pp. 18-38 


\section{P.L. LORENZO CADARSO}

afrenta a terceros, punible entonces por la ley. Haciendo siempre una clara distinción con la infidelidad conyugal, porque en este asunto no había dudas sobre su carácter de delito penal grave, incluso para los intelectuales más tolerantes, como era el caso de Luis Vives:

«...la castidad que tú tienes no es tuya, sino de tu marido; el cual te la entregó y puso en tu mano y te la encomendó y mandó que la guardases más que a tu vida propia.... $\rangle^{44}$

Sin embargo, no estaba muy claro si la honorabilidad pasaba a ser propiedad del marido en el momento del matrimonio o si lo era ya desde que se comprometía el desposorio. Es más, los hombres que simplemente amaban, cohabitaban o aspiraban a casarse con una determinada mujer, solían atribuirse similares prerrogativas de propiedad absoluta. En estos casos, de cualquier manera, el tipo de venganza cambia, no suele haber pena de muerte, sino simplemente palizas, acompañadas muy frecuentemente por la práctica de marcarles la cara, es decir, hacerles un corte en la mejilla con un cuchillo. Era ésta una manera de identificarlas a perpetuidad como mujeres traidoras.

Este tipo de atropellos llegaban con mucha menor frecuencia que los anteriores a los tribunales, ya que las víctimas y sus familias, considerando como prioritario mantener el buen nombre de la mujer, preferían ocultar lo sucedido y un pleito judicial exigía darle publicidad al caso.

Vamos a centrar nuestro estudio empírico en una serie de casos casi similares que sucedieron en Logroño a comienzos del siglo XVII. Según un memorial enviado al Consejo de Castilla en 1608 por una de las víctimas, la causa de la proliferación de este tipo de delitos era la inhibición de las autoridades judiciales ${ }^{45}$, y desde luego que no le faltaba razón. Pero ocurre que las autoridades locales no se sentían apoyadas por sus superiores jerárquicos de la Chancillería de Valladolid y del Consejo de Castilla; es más, el 20 de febrero de 1574, ante la llegada a Logroño de un corregidor riguroso, amigo de no inhibirse en los asuntos de la «vida privada» de los vecinos, el Consejo expidió una Provisión Real ordenándole que no lo hiciera de no mediar denuncias, ya que con ello no conseguía sino encrespar más los ánimos y hacer difícil la reconciliación de las partes ${ }^{46}$.

En 1607 sucedieron ya varios casos escandalosos y que quedaron impunes debido al escaso interés que el corregidor, don Diego de Miranda, mostró por ellos:

«....saliendo doña Gregoria de Salcedo, doncella principal, de una iglesia y habiendo comulgado en ella, le aguardó un Diego de Yanguas y con una daga la intentó cruzar la cara y la tiró algunos golpes, y si una mujer principal que iba con ella no se pusiera de por medio, con mucho riesgo suyo, y diera voces, viniera a tener efecto el dcho. delito. Y por estar favorecido el dcho. Diego de Yanguas no se ha procedido contra él. $Y$ seis o siete meses antes, poco más o menos, un hombre quiso asimismo cruzar la cara a Catalina, viuda honrada, y la dejó herida y maltratada y tampoco fue preso, ni se hizo diligencia, y lo mismo ha sucedido con otros casos... ${ }^{47}$

Todos los personajes implicados en estos sucesos, hombres y mujeres, pertenecian a los principales linajes hidalgos de la ciudad, implicados por aquel entonces en duras

44. cit. en ibid. p. 140

45. A.H.N., Consejos, leg. 27.996

46. Archivo Municipal de Logroño, leg. 9-49

47. A.H.N., Consejos, leg. 27.996 


\section{LOS MALOS TRATOS A LAS MUJERES EN CASTILLA EN EL SIGLO XVII}

luchas intestinas y por el control del Ayuntamiento ${ }^{48}$, y lo mismo ocurría con los que participaron en los hechos de 1608 , éstos ya más graves ${ }^{49}$ :

«...teniendo Juan de Falces en su casa y compañia a doña Filipa, su hermana, y siendo como es doncella muy honesta y recogida y de las de más ejemplar vida $y$ costumbres de la dcha. ciudad, hijadalga de padre y madre, sin haber dado causa ni ocasión a don Francisco Anguiano para que la hiciesen ofensa, estando ausente Juan de Falces de la dcha. ciudad, en trece de mayo pasado, el dcho. Fco. Anguiano, sobre acuerdo y caso pensando, aguardó y espió, como vecino que es que doña Ana de Zúñiga, mujer del dcho.d Juan de Falces, saliese de casa y quedase sola la dcha. Doña Filipa. Y entrando con el mayor secreto que pudo, la llamó vellaca desvergonzada y le dijo otras palabras injuriosas y le dio de bofetadas y muchos golpes y porrazos, dejándola acardenalada y llorando...»

La familia de la muchacha prefirió ocultar lo sucedido y no denunciarlo al corregidor. Había pocas posibilidades de que éste actuara con rigor y las malas lenguas no tardarían en poner en duda la honorabilidad de Felipa. Fue un error, porque don Francisco Anguiano no se conformó con lo que había hecho:

«...y no contento con lo susodicho, el sábado siguiente, que se contaban diez y siete de mayo, hacia las diez de la mañana, espió en la misma forma a que se fuese de la casa doña Ana de Zúñiga a misa, y estando cerrada la puerta de la escalera la abrió y entró en la sala donde estaba descuidada la dcha. doña Filipa haciendo su labor, y con un cuchillo que llevaba para el efecto le dio dos cuchilladas en los carrillos, que cada una de ellas le llega desde la oreja a la boca, y otra herida en la mano izquierda...»

La familia denunció de inmediato el asunto al corregidor, pero éste se limitó a dictar auto de procesamiento, sin hacer ninguna diligencia para apresar al agresor. La familia Falces era rica y no tardó en llevar el caso ante el Consejo de Castilla más que unos días, pero para cuando éste trató de intervenir -todo con suma parsimonia-, don Francisco Anguiano ya había huido a Navarra y asentado plaza en el Regimiento de Caballería Ligera del Condestable. El Consejo se inhibió en el caso y el asunto pasó a tramitarse ante el Alcalde de Guardas de Pamplona. Para entonces casi había transcurrido, era el 23 de marzo de 1609 , un año.

Por tristes que sean estos sucesos, no se debe olvidar que todos están protagonizados por gente poderosa y rica, que podía suplir con su dinero y sus influencias, aunque sólo fuera en parte, el desinterés de las autoridades judiciales. Pero cuando las víctimas eran mujeres sin recursos, la situación se tornaba ya patética. Este es, por ejemplo, el caso que narra el procurador de María de Benito, vecina de Logroño, en un memorial enviado al Consejo en agosto de $1611^{50}$ :

«...hacia dos meses y medio que estando Maria de Benito a su puerta una noche después de anochecido, Sebastián Pérez pasó por ella e dijola muchas palabras, procurando, como ya lo habia procurado antes, solicitarla deshonestamente, y habia pasado su atrevimiento tan adelante que la habia querido forzar; e como la susodicha

48. Gracias al Proyecto de Historia de Logroño, dirigido por el Dr. J.L. Gómez Urdáñez, contamos ya con un profundo conocimiento de la élite urbana de la ciudad. Su publicación verá la luz en el año 1992.

49. A.H.N., Consejos, leg. 27.996

50. Archivo General de Simancas, Registro General del Sello, agosto de 1611 
se habia defendido, el dcho. acusado la habia dicho que juraba a Dios que le habia de hacer una burla muy pesada que le recordase a ella y a su marido, y haciéndole muchos juros y amenazas (...) y la misma noche les habia puesto a la puerta unos grandes cuernos, con un rótulo que decia: CORNUDO, PARA QUE LOS SUFRAS...»

El desinterés de las autoridades judiciales por estos asuntos hacía a los agresores cada vez más osados (en teoría, colocar un pasquín podía ser castigado con varios años de galeras o incluso con la pena de muerte). Al mismo tiempo, las víctimas, que se sentian desprotegidas e indignadas, era fácil que pretendiesen tomarse la justicia por su mano. Todo esto se comprobó a la mañana siguiente, cuando se descubrió el pasquín de los cuernos:

\begin{abstract}
«...e después pasó el acusado por la puerta, muy disimulado e procurando saber de los vecinos de quién se sospechaba que hubiese hecho el delito, e como le hubiere visto la mujer, con la cólera que tenia habia querido arremeter a él, y el susodicho, sin otra ocasión, había metido mano a la espada y le habia dado una estocada por la barriga, de que la habia herido y estaba a punto de muerte y en gran peligro por estar preñada...»
\end{abstract}

El alcalde mayor, en vez de apresar de inmediato al agresor, se entretuvo en hacer primero un reconocimiento meticuloso de los testigos, dando tiempo de sobra al agresor para que se refugiara en un convento. Su obligación hubiera sido entonces solicitar una Provisión Real al Consejo para que se le retirara la protección eclesiástica, pero no lo hizo, según las víctimas, porque:

«...por ser dcho. alcalde mayor gran amigo del acusado (...) Y asi habia quedado tan atroz delito sin castigo y se andaba públicamente paseando de noche e de dia por la ciudad a vista de la justicia...»

El 28 de agosto de 1611, casi seis meses después de los hechos, el Consejo de Castilla inició los trámites para enviar un juez de comisión y no tenemos constancia de que éste llegase nunca a Logroño.

\title{
B) Las mujeres adúlteras
}

De entre todas las ofensas que una mujer podía hacer a un hombre del siglo XVII, el adulterio era, sin duda, la más grave. Ya en muchos fueros medievales, ante la gravedad del delito, se consentía que el marido ejecutara por sí mismo a la esposa infiel, sin ser procesado de probar que «siempre había llevado buena vida»". La legislación desarrollada en los siglos XVI Y XVII no era, ni muchos menos, tan permisiva, pero en la Nueva Recopilación de 1567 se recogía el derecho del esposo a ejecutar a su mujer y a su amante de inmediato, siempre que los sorprendiera in fraganti. También existía la posibilidad de que las autoridades judiciales entregaran a los adúlteros sentenciados al marido para que éste los ejecutase. Asimismo, los maridos que consentían el adulterio de sus esposas podían ser sometidos a infamia pública ${ }^{52}$.

51. Por ejemplo, en los fueros de LLanes y de Ledesma, cit. en R. Pastor, art. cit., p. 195

52. vid., Deleito y Piñuela, J., ob. cit., pp. 74-75 
De todos modos, a medida que fue avanzando el siglo XVI y sobre todo durante el XVII, aumentaron las críticas a tales costumbres asesinas, llevadas a cabo, principalmente, por la Iglesia ${ }^{53}$. Los clérigos, además, protegían habitualmente a las adúlteras del furor de su esposos y, poco a poco, las autoridades judiciales fueron haciendo también todo lo posible por evitar los asesinatos ${ }^{54}$. Había imperativos legales que hacían difícil que un juez pudiera inhibirse ante los asesinatos de adúlteras, dado que la ley les exigía actuar de oficio, sin esperar a que se presentase denuncia. Esta actitud de jueces y clérigos ante el adulterio puso las cosas difíciles a los maridos que deseasen tomarse la justicia por su mano, de modo que todos los indicios parecen indicar que el asesinato de las adúlteras pasó a ser una práctica ocasional.

Probablemente, aunque esto sea pura hipótesis, hubiera en el siglo XVII muchos más cornudos consentidos que cornudos asesinos, no en vano la figura social del cornudo ingenuo, paciente o interesado se convirtió en el siglo XVII en uno de los temas literarios más tratados ${ }^{55}$. A la par, y probablemente en intima relación con lo que acabamos de decir, las comedias de honor aupaban a la condición de héroes, de hombres modélicos, a quienes eran capaces de arriesgar su vida y su hacienda para lavar con sangre las afrentas contra su honor. Esto parece estar demostrándonos que, independientemente de la actitud de jueces y clérigos, entre el pueblo no se consideraba un delito asesinar a la adúltera ${ }^{56}$.

Un porcentaje desconocido de los adulterios descubiertos lograban ser solventados en el más absoluto secreto, porque, no lo olvidemos, de hacerse público el hecho, sobre todos los hijos de la pareja recaía el fantasma de la ilegitimidad. En Navarrete (La Rioja), por ejemplo, en 1656 se supo por cauces muy confidenciales que era posible que una mujer le estuviera siendo infiel a su marido. Rápidamente, el 19 de agosto, se reunieron en consejo el marido, el hermanastro, la madrastra, el padre, el cuñado y el suegro de Francisca Revollo, la presunta adúltera. Allí mismo fue juzgada, sentenciada y ejecutada por estrangulamiento, todo en el más absoluto secreto: estaba ya embarazada y no había tiempo que perder ${ }^{57}$. Le pusieron un collar de tela para disimular la herida y llamaron a un médico, amigo de la familia, para que certificase que había fallecido de muerte natural. A éste le acompañó un cirujano, que sospechó, por el aspecto del cadáver, lo que había ocurrido y pidió que le quitaran el collar. Uno de los familiares lo sacó de la sala $y$, entre amenazas, se le obligó a firmar el certificado de defunción falso.

Alguien, probablemente el mismo cirujano, les denunció en secreto ante la Chancillería, pero no había pruebas y, además, uno de los implicados (Fco. Revollo, el padre) era familiar del Sto. Oficio, de modo que el Consejo de Castilla intervino en el caso ordenando que el conocimiento pasara al Tribunal de la Inquisición, el cual se limitó a archivarlo.

53. vid., Mariló Vigil, ob. cit., pp. 148-156

54. En las memorias de Catalina de Erauso, ob. cit., pp. 71-75 se narra un ejemplo.

55. Quevedo, que les dedica múltiples comentarios a lo largo de su obra, los coloca en el infierno, cfr., Fco. Quevedo, Los Sueños, Madrid, 1977, p. 40. También son tratados por el portugués Piñeiro en su Pratilogía, Navarrete en el entremés El tahúr Celoso, Santos en Día y noche de Madrid, Quiñones de Benavente en El marido flemático y muy a menudo en la novela picaresca del Siglo de Oro.

56. Alonso de Contreras, en sus memorias, no tuvo ningún reparo en confesar haber asesinado, con premeditación, al amante de su esposa y haber intentado otro tanto con el de su amante. cfr., Alonso de Contreras, Vida del capitán Contreras, Barcelona, 1982, pp. 84-88 y 96-97

57. A.H.N., Consejos leg. 25.630 
En el momento en que el secreto no se podía guardar, resultaba peligroso y contraproducente para el esposo ejecutar a la adúltera, de modo que, pasado el primer momento de cólera, se solía preferir la separación e ingresar a la mujer en un convento. En Logroño, en 1680, un mercader supo a la vuelta de uno de sus viajes que había rumores sobre la fidelidad de su mujer ${ }^{58}$ :

«...de unos días a esta parte ha estado melancólico y triste, sin que haya dicho la causa que tenia para ello...»

Esto declararía su esposa más tarde. Pero una noche, después de cenar, bastó una pequeña discusión para precipitar los acontecimientos:

«...habia querido e intentado matar a la susodicha con una espada, echando mucho votos y retos el dcho. Pedro Igay, diciendo que habia de acabar con todo de una vez...»

La intervención primero de un criado, que sujetó y encerró al iracundo marido y avisó al corregidor y, posteriormente, la protección que recibió la mujer de los eclesiásticos y del propio corregidor evitaron que se consumara el crimen. El esposo se negó a declarar los motivos que le habían inducido, alegando que podían afectar a su honra. El Consejo de Castilla, ante quien fue elevado el caso, decretó la separación, ingresando a la mujer en un convento de monjas de Herce (La Rioja) y obligando al marido a pasarle una pensión de 200 ducados al año.

Trece años después, la mujer huyó del convento, enferma y hambrienta, porque su esposo le había pagado 200 ducados en todo ese tiempo, en lugar de los 2.600 que le correspondían. Sólo entonces, para lograr que su mujer fuera recluida de nuevo (el Consejo se resistía a hacerlo por razones humanitarias), declaró la verdadera razón de sus actos:

«...haber tenido bastantes sospechas de que su mujer le faltaba a la obligación de la fidelidad en el matrimonio...»

Con la ayuda de su hermano, que era ayuda de Cámara de la reina, logró la mujer que se separaran los bienes gananciales. Le correspondieron 7.000 de los 14.000 ducados que dijo poseer su marido (cuando el 3-1-1700 murió, se supo que su hacienda valía 80.000 ducados).

Tantos años de pleitos y el pago de un pensión de manutención no estaban, evidentemente, al alcance de cualquiera, por lo que muchos maridos que se sabían engañados tenían que buscar otros métodos. Algunos ni tan siquiera tenían la posibilidad de asesinar a su esposa confiando en que las autoridades no intervinieran o le impusieran una pena leve, porque los amantes de sus mujeres eran tan poderosos que llegarían a donde no lo hicieran los tribunales. Para un hombre pobre era complicado y arriesgado no fingir ignorancia y usar la violencia: un amante poderoso era mucho más peligroso que los jueces.

Este fue el caso de un jornalero de Logroño, que en 1636 supo que su mujer se entendía con uno de los hombres más poderosos de la ciudad, hidalgo y regidor perpetuo.

58. A.H.N., Consejos, leg. 36.589 
Vivía en habitaciones subarrendadas y todos los días tenía que salir al campo a trabajar, dejando sola a su mujer. Aprovechando esta situación, el regidor presionaba a los caseros para que le franquearan la puerta del dormitorio de su amada. El jornalero no osó denunciar el caso y, como primera medida, se trasladó cinco veces de casa en busca de un casero que no permitiese entrar al regidor y garantizase el aislamiento de su esposa. Todo fue en vano, y optó por irse de la ciudad, siguiendo los consejos de un clérigo, de lo cual se lamentaba el corregidor ante el Consejo:

«...se tomó por medio para la quietud del casado a quien se agraviaba que se fuese de la ciudad a vivir a otra parte y se ejecutó esto con mucha ofensa de la república y deslustre de la justicia, de la que se pudo pensar que no tenia poder para amparar a los vecinos humildes della, viendo que le habia sido forzoso a este pobre hombre dejar su patria y salirse desterrado con su familia para librarse de la violencia de un particular. Y lo peor es que aun esto no le bastó, pues al lugar de Alberite, donde se retiró, fue el dcho. Pedro Pérez a continuar su intento.... ${ }^{59}$

La otra medida que tomó el jornalero fue amedrentar a su esposa, la cual, según declaraban algunos testigos, era tan víctima como él de lo que estaba ocurriendo:

«...sabe este testigo que Pedro Pérez inquieta a la dcha. mujer casada, no la dejando vivir en paz ni sosegar con el dcho. su marido; y esto lo sabe por habérselo oido decir a la misma y porque muchas veces ha visto y entendido que el marido de la misma la ha dado muchos golpes y la ha hecho muchas heridas y cardenales, por celos que ha tenido del dcho. Pedro Pérez y él la ha oido quejar de las violencias que le quiere hacer en su casa...»

\section{EPILOGO}

Los malos tratos a las mujeres no eran algo ocasional, sino que estaban en íntima relación con el orden social vigente, en el que la reputación social del individuo y la honorabilidad de su linaje constituían asuntos prioritarios. Las mujeres ocupaban un papel importante en los mecanismos de transmisión y conservación de un determinado status dentro de la jerarquía social. Controlarlas era una garantía de que los objetivos socio-económicos de su familia y de su marido no serían puestos en peligro.

Pero con esto, lógicamente, no basta para explicar la condición de inferioridad jurídica y moral que les tocó vivir a las mujeres del Antiguo Régimen y mucho menos para explicar los abusos de que eran objeto. Se hace necesario también tener en cuenta ciertas ideas y conceptos que ya eran viejos en el siglo XVII. Entre ellos cabe destacar la extremada misoginia, que terminaba por dudar de que hubiese otro modo de conseguir que las mujeres no faltaran a su deber que usar la mano dura, y la exaltación, a través de la literatura y de la propia legislación, de la idea de que era un deber irrenunciable en el hombre el defender su reputación social, con sangre si era preciso.

En la práctica totalidad de los casos que hemos narrado hay hidalgos implicados, los hombres como agresores y las mujeres como víctimas. Los miembros de este grupo

59. A.H.N., Consejos, leg. 32.346 
social no podían permitirse ni un solo error si querían seguir figurando entre los privilegiados; por tanto, aislaban rigurosamente a sus mujeres, respondían con violencia ante cualquier afrenta a su buen nombre, los matrimonios se concertaban de acuerdo con una rigurosa estrategia, etc.. Así, la mujeres hidalgas fueron, sin duda, las más castigadas por todas las prácticas antifemeninas existentes en la época.

Por último, el amor no era tenido en cuenta a la hora de concertar matrimonios, ni justificaba socialmente ningún desliz -sobre todo si era femenino-, de modo que se convirtió en un asunto extramatrimonial, muy a menudo trágico en sus consecuencias, ya que resultaba una amenaza para los objetivos sociales y económicos de las élites. 